\title{
An Update on Systemic Sclerosis and its Perioperative Management
}

\author{
Zyad J. Carr ${ }^{1,2}$ (1) John Klick ${ }^{3,4} \cdot$ Brittany J. McDowell $^{5,6} \cdot$ Jean G. Charchaflieh ${ }^{1,2} \cdot$ Kunal Karamchandani $^{5,6}$ \\ Published online: 29 August 2020 \\ (C) Springer Science+Business Media, LLC, part of Springer Nature 2020
}

\begin{abstract}
Purpose of Review Systemic sclerosis or scleroderma (SSc) is a systemic, immune-mediated disease characterized by abnormal cutaneous and organ-based fibrosis that results in progressive end-organ dysfunction and decreased survival. SSc results in significant challenges for the practicing anesthesiologist due to its rarity, multi-system involvement, and limited evidence-based guidance for optimal perioperative care. In this update, we briefly discuss the recent evidence on the pathophysiology and current management of SSc, review the anesthesia-related literature, and extrapolate these observations into an optimal perioperative strategy for the care of SSc patients.

Recent Findings Evidence shows that patients with SSc demonstrate an increased risk for perioperative myocardial infarction, high rates of interstitial lung disease, pulmonary arterial hypertension, neurological disease, gastric dysmotility disorders, and challenging airway management, all findings that may result in suboptimal perioperative outcomes.

Summary Advances in SSc medical management have resulted in improved survival, likely increasing the number of patients who will be exposed to perioperative care. Optimal perioperative management and risk stratification should expand beyond the well-described airway challenges and consider numerous systemic manifestations of systemic sclerosis such as pulmonary arterial hypertension, interstitial lung disease, and cardiac sequelae.
\end{abstract}

Keywords Systemic sclerosis $\cdot$ Scleroderma $\cdot$ Anesthesia $\cdot$ Perioperative

\section{Introduction}

Systemic sclerosis is an autoimmune disorder characterized by small-vessel vasculopathy, abnormal collagen deposition with fibrosis, and autoantibody-mediated immune dysfunction characteristically observed in the integumentary system.

This article is part of the Topical Collection on Preoperative Evaluation

Zyad J. Carr

zyad.carr@yale.edu

1 Department of Anesthesiology, Yale New Haven Hospital, New Haven, CT 06510, USA

2 Yale University School of Medicine, New Haven, CT 06510, USA

3 Department of Anesthesiology, University of Vermont Medical Center, Burlington, VT 05405, USA

4 Larner College of Medicine at The University of Vermont, Burlington, VT 05405, USA

5 Department of Anesthesiology, Penn State Health Milton S. Hershey Medical Center, Hershey, PA 17033, USA

6 Penn State School of Medicine, Hershey, PA 17033, USA
In addition, progressive fibrosis of visceral organs such as the heart, the lungs, the kidneys, and the gastrointestinal tract results in substantial morbidity and mortality. Proposed mechanisms highlight the importance of small-vessel vasculopathy, with broad interplay of genetic and environmental triggers, as a causative factor for both cutaneous and visceral manifestations of SSc [1]. Ultimately, as small-vessel vasculopathy leads to recurrent ischemia-reperfusion injury, vessel elasticity is lost, and the pathognomonic development of fibrosis ensues, resulting in the classic features of SSc. First classified in 1988, it can be broadly divided into limited or diffuse cutaneous disease although many subtypes exist (limited cutaneous, diffuse cutaneous, sine, and overlap syndromes). The limited disease is of less severity than the diffuse, with less internal organ involvement and confinement of skin thickening to extensor surfaces of the body. Patients diagnosed with diffuse cutaneous SSc comprise $40 \%$ of patients and typically have proximal limb involvement, high rates of fibrotic lung changes, and increased risk for renal and cardiac involvement. Since 1980, SSc has been classified utilizing the American Rheumatological College criteria, followed by the LeRoyMedsger criteria, and has undergone continuous refinement since that time $[2,3]$. The latest iteration was refined in 2013 
in collaboration with the American College of Rheumatology and the European League against Rheumatism (ACR/ EULAR). It demonstrates a $91 \%$ sensitivity and $92 \%$ specificity, and is summarized in Table 1 [4]. SSc is rare and demonstrates wide geographical variation. In the USA, the incidence is approximately $13.9 / 1,000,000$ with a female to male ratio of 9.7:1 [5]. With improvements in management, survival in patients with SSc has improved over time, and the 10year survival is $66 \%$ after diagnosis [6]. The EULAR Scleroderma Trials and Research database has demonstrated that $55 \%$ of deaths can be directly attributable to SSc and $41 \%$ are not directly associated with the disease [7]. Of the SScrelated deaths, visceral organ involvement account for most deaths, with pulmonary fibrosis (19\%), pulmonary arterial hypertension (14\%), and myocardial disease (14\%) comprising the majority of causes. Of the non-SSc-related deaths, cancer (13\%), infection (13\%) and cardiovascular disease (12\%) comprised most of the deaths.

\section{Preoperative Considerations}

Patients with SSc presenting for surgery can pose multiple challenges for the anesthesiologist, an observation that has been acknowledged in the early anesthesia literature [8]. Due to the rare incidence of SSc, few clinical studies have been published on perioperative care; therefore, preoperative evaluation should quantify the extent and severity of SScrelated disease manifestations and their perioperative implications. Fortunately, significant progress has been made in characterizing the general medical care of patients with SSc and this can be extrapolated to optimal perioperative management.

The frequency of neurological involvement is between 1 and $40 \%$ in SSc patients and can be categorized into distinct central, peripheral, and autonomic nervous system involvement. Patients with anti-Scl70 and U1RNP antibodies appear to have higher risk for neurological involvement [1, 9]. Epilepsy (42.6\%) and headache (18.8\%) predominate the central nervous system conditions observed in an SSc population [10]. In addition, a high psychiatric burden is also observed, particularly depression (30-40\%) and anxiety (25-64\%). Peripheral neuropathy related to nerve entrapment is common in $\mathrm{SSc}$ with peripheral sensorimotor polyneuropathy (14.25\%), trigeminal neuropathy $(16.52 \%)$, and carpal tunnel syndrome $(6.56 \%)$ comprising the majority of diagnoses. Secondary Raynaud's phenomenon is a typical neurovascular complication in SSc and is characterized by collagen infiltration of distal blood vessels in the hand, rather than the classically described transient spasm of distal arteries. Severe cases may result in pain, numbness, ulcers, and loss of fingertips. At least one report describes severe pain with intravenous propofol administration in a patient with secondary Raynaud's phenomenon although this presumed association was controversial [11, 12]. Autonomic nervous system
Table 1 American College of Rheumatology/European League Against Rheumatism SSc classification criteria for the diagnosis of systemic sclerosis. Note the critical role that physical examination findings play in the diagnosis of SSc and the prominence of pulmonary arterial hypertension and interstitial lung disease
American College of Rheumatology/European League Against Rheumatism classification criteria for the diagnosis of systemic sclerosis $\dagger$

\begin{tabular}{lll}
\hline Systemic manifestations & Features & Scoreł \\
\hline $\begin{array}{l}\text { Skin thickening of bilateral distal fingers extending to the } \\
\text { metacarpophalangeal joints (sufficient criterion) }\end{array}$ & n/a & 9 \\
$\begin{array}{l}\text { Skin thickening of the fingers } \\
\text { Puffiness }\end{array}$ & 2 \\
Lesions on the tip of fingers (count the highest score) & Sclerodactyly evident between & 4 \\
& Distal finger ulcers & 2 \\
Evidence of telangiectasia & Distal finger pitting scar & 3 \\
Evidence of abnormal nailfold capillaries & & 2 \\
Evidence of pulmonary arterial hypertension and/or & & 2 \\
interstitial lung disease (maximum score: 2) & Pulmonary arterial hypertension & 2 \\
Evidence of Raynaud's phenomenon & Interstitial lung disease & 2 \\
Evidence of SSc-related autoantibodies (maximum score: 3) & Anti-centromere (3) & 3 \\
& Anti-topoisomerase I (3) & 3 \\
\end{tabular}

$M C P$ metacarpophalangeal joints, $P I P$ proximal interphalangeal joints, $S S c$ systemic sclerosis Adapted from: van den Hoogen F, Kanna D, Fransen J et al. Classification Criteria for Systemic Sclerosis: An American College of Rheumatology/European League Against Rheumatism Collaborative Initiative. (2013)

$\$$ Total score is determined by adding the maximum score achieved in each category. $\geq 9$ is classified as definite $\mathrm{SSc}$ 
disorders are common in SSc, and studies have reported an incidence of $79 \%$ for parasympathetic dysfunction and 55\% for sympathetic dysfunction [13, 14]. SSc patients demonstrate a high incidence of parasympathetic autonomic instability as shown by orthostatic hypotension, blunted rise in blood pressure with sustained hand grip, and decreased compensatory heart rate variation with Valsalva maneuvers [15]. Neurological conditions should be carefully reviewed in all preoperative patients with $\mathrm{SSc}$, with an emphasis on eliciting symptoms of autonomic dysfunction (e.g., orthostatic hypotension) and consideration of potential intraoperative positioning challenges for the chosen surgical procedure.

Cardiac involvement is prevalent in SSc. Brought upon by the sequelae of pathological extracellular matrix deposition, patients demonstrate a wide variety of cardiac conditions including progressive congestive heart failure, diastolic dysfunction, pericardial involvement, or arrhythmias. It may be classified as primary or secondary cardiac involvement. Secondary involvement is defined as the cumulative effect of age-related comorbid conditions in conjunction with progressive SSc-related fibrosis. SSc with cardiac involvement, particularly in those with the diffuse subtype of SSc, is related to higher mortality risk $[16,17 \bullet \bullet]$. A three-fold increase in myocardial infarction has been documented in a retrospective matched incident cohort study of 1239 patients with SSc [18]. There is some evidence that SSc-related cardiac morbidity carries over to the perioperative period. For example, SScrelated sinoatrial involvement may result in perioperative dysrhythmias that may be enhanced by volatile anesthetics and other administered anesthetic drugs. This observation is highlighted by published reports of intraoperative cardiovascular events related to dysrhythmia and pulseless electrical activity [19-21]. Furthermore, one study has examined the association between SSc and perioperative cardiovascular risk for inpatient surgical procedures and found an independent association between SSc and perioperative myocardial infarction but not for ischemic stroke, cardiac arrest, or acute heart failure [22••]. Careful evaluation of the cardiovascular system, particularly in patients with risk factors for the development of SSc-related cardiomyopathy (male sex, diffuse SSc, presence of anti-topoisomerase and other antibodies, evidence of interstitial lung disease (ILD), and higher scores on the disability index) should be encouraged. An elicited history of dyspnea on exertion, palpitations, chest pain, or syncope should encourage the perioperative physician to pursue further characterization of SSc-related cardiac disease. Given the high incidence of congestive heart failure, dysrhythmias and pericardial disease, preoperative echocardiography, and electrocardiography (ECG) should be considered prior to moderate to high-risk surgical procedures.

SSc-related interstitial lung disease (ILD) and pulmonary arterial hypertension $(\mathrm{PAH})$ are the two most common causes of SSc-related mortality and are believed to be related to vasculopathy of the small pulmonary arteries. PAH is rare with less than 1000 cases per year but occurs in approximately $10 \%$ of patients with SSc, commonly manifests with exertional dyspnea and results in a median survival of 3 years [23, 24]. Initial treatment usually involves sildenafil (class B evidence) to improve exercise tolerance and anticoagulation with warfarin (class B evidence). Newer treatments include endothelin antagonists and prostacyclin analogues. Little is known about the specific perioperative implications of SSc-related PAH although the anesthesiologist should be prepared to manage right ventricular dysfunction secondary to elevated pulmonary vascular resistance. Separately, pulmonary hypertension related to ILD or SScrelated cardiac involvement may increase both morbidity and mortality in the perioperative period and may be present in 8 $12 \%$ of SSC patients $[23,25 \cdot]$. ILD may present with mild changes in functional capacity before any radiographical evidence with the most common early change being a reduced forced vital capacity (FVC) with a normal forced expiratory volume, 1 st second/forced vital capacity $\left(\mathrm{FEV}_{1} / \mathrm{FVC}\right)$ ratio. Similar to pulmonary fibrosis due to other causes, the diffusing capacity for carbon monoxide (DLCO) correlates with the extent of gas exchange dysfunction [26]. Patients may present for surgery while being treated with disease-modifying agents such as cyclophosphamide, mycophenolate mofetil, and pirfenidone, and a high level of vigilance for potential drug interactions is warranted during the preoperative assessment. Select perioperative implications of routine disease-modifying agents in SSc have been summarized in Table 2.

Given the prominence of PAH and ILD in SSc-related mortality and morbidity, focused pulmonary assessment is useful for perioperative risk stratification and allows for early detection of perioperative complications. Reduced functional capacity in patients with scleroderma-related PAH and ILD may be detected through abnormalities in the 6-min walk test and the University of California in San Diego Shortness of Breath Questionnaire (UCSD SOBQ). The UCSD SOBQ has demonstrated responsiveness to negative changes in patients with both ILD and PAH [38]. The 6-min walk test remains the most commonly used tool to monitor functional capacity in patients with ILD. Its use has not been fully validated in this population, but it has demonstrated efficacy in the differentiation of clinically meaningful PAH and ILD in at least one study, lending its utility in preoperative risk stratification [39-41]. Radiographic pulmonary assessment should be considered in preoperative patients with symptoms of shortness of breath, dyspnea on exertion, or supplemental oxygen use. On high-resolution computed tomography (HRCT), SSc-related ILD is usually characterized as non-specific interstitial pneumonitis. Impulse oscillometry can detect subtle small airway dysfunction, and small airway abnormalities are found in $25 \%$ of SSc patients [42]. The small airway dysfunction was more common in patients with limited cutaneous SSc compared with the more severe diffuse SSc and was not appreciated on 
Table 2 Select perioperative implications of medications used in the treatment of systemic sclerosis. Substantial progress has been made in the treatment of SSc using disease-modifying agents [27-37]

\begin{tabular}{|c|c|c|}
\hline Medication & SSc use & Perioperative implications \\
\hline Calcium channel blockers & Raynaud's phenomenon & Generally beneficial; reduces cardiac morbidity after non-cardiac surgery ${ }^{25}$ \\
\hline Cyclophosphamide & ILD & Immunosuppression; drug-related cardiomyopathy \\
\hline Mycophenolic acid & ILD & Immunosuppression, potential enhancement with $\mathrm{PPI}^{26}$ \\
\hline Azathioprine & ILD & Transient antagonism of atracurium, vecuronium, and pancuronium ${ }^{27}$. \\
\hline Epoprostenol & PAH & $\uparrow$ Risk of blood loss in LVAD placement ${ }^{28}$ \\
\hline Endothelin receptor antagonists* & $\mathrm{PAH}$ & $\begin{array}{l}\text { May impair vasoconstriction during hemorrhage }{ }^{29} \text {. } \\
\text { Negative lusitropic myocardial effects }\end{array}$ \\
\hline Phosphodiesterase-5 inhibitors** & $\mathrm{PAH}$, digital ulcers & $\begin{array}{l}\text { Risk of ischemic optic neuropathy }{ }^{31} \text {, reduction in biventricular } \\
\text { systolic function }{ }^{32} \text {, cerebral venous thrombosis }{ }^{33}\end{array}$ \\
\hline Glucocorticoids & Reduce SSc lesion inflammation & May precipitate scleroderma renal crisis \\
\hline Methotrexate & Inflammatory arthritis & $\begin{array}{l}\text { Thrombocytopenia; interstitial pneumonitis; } \uparrow \text { pneumonia; } \\
\text { possible protective effect for MACE }\end{array}$ \\
\hline Chelating agents $\dagger$ & SSc calcinosis, fibrosis & Nephropathy, aplasia, polymyositis (penicillamine) \\
\hline Bisphosphonates $\ddagger$ & $\mathrm{SSc}$ calcinosis & Modest $\uparrow$ risk of atrial fibrillation ${ }^{35}$ \\
\hline Rituximab & Skin fibrosis & $\begin{array}{l}\text { Infusion-related reactions; progressive multifocal } \\
\text { leukoencephalopathy; mucocutaneous reactions }\end{array}$ \\
\hline
\end{tabular}

ILD interstitial lung disease, PPI proton pump inhibitor, $L V A D$ left ventricular assist device, $P A H$ pulmonary arterial hypertension, SSC systemic sclerosis, MACE major adverse cardiovascular events

*Ambrisentan, bosentan, macitentan

**Sildenafil, tadalafil, vardenafil, avanafil

$†$ Penicillamine (less common)

\$Alendronate, ibandronate, risedronate, zoledronic (no longer recommended in SSc)

$\uparrow$ increased

standard pulmonary function tests. Large airway obstruction was rare, but common defects in pulmonary function testing, such as reduced DLCO and total lung capacity (TLC), correlate with worsening SSc lung involvement. This suggests that a high level of vigilance for the presence of reactive airway disease should be considered in patients with SSc even when asymptomatic and that preoperative pulmonary function testing may provide useful guidance for preoperative optimization. In addition, rising inflammatory markers such as an erythrocyte sedimentation rate of $\geq 20 \mathrm{~mm} / \mathrm{h}$ and C-reactive protein $\geq 5 \mathrm{mg} / \mathrm{L}$ are correlated with deterioration in pulmonary function tests and pulmonary arterial hypertension, suggesting their utility in the preoperative assessment of patients with SSc [43].

Esophageal dysmotility disorders feature prominently in SSc with dysphagia and gastroesophageal reflux disease (GERD) occurring in 70\% of patients [44]. Gastric involvement and hypotonic lower esophageal sphincter tone result in impaired emptying and food stasis. Due to the potential risk of perioperative aspiration, these abnormalities should be taken into consideration when selecting the anesthetic technique. Other severe gastrointestinal manifestations, including pseudo-obstruction, intestinal dysmotility disorders, volvulus, and intestinal telangiectasia, may signal higher mortality risk and potentially increase the perioperative risk profile $[45,46]$.
Gastrointestinal manifestations may also indicate the presence of malnutrition (20\% of patients), sarcopenia, vitamin C deficiency, and worsening lung disease [47, 48]. SSc-related primary biliary cirrhosis (PBC) has been shown to occur in $2-$ $22 \%$, but is associated with improved outcomes compared with other forms of PBC [49, 50]. Regardless, the presence of PBC alone has not been shown to be associated with increased perioperative morbidity or mortality [51].

SSc-related renal impairment occurs in approximately $4-6 \%$ of patients, with the worst outcomes being encountered in patients with scleroderma renal crisis (SRC), a form of severe renal decompensation [52]. The adoption of angiotensin-converting enzyme inhibitors (ACEIs) has improved outcomes in SRC but overall survival remains poor, particularly if the disease is severe enough to necessitate dialysis [53]. Its triggers are unclear, but characteristic presentations of SRC include features of malignant hypertension, encephalopathy, and evidence of congestive heart failure.

SSc patients have an increased risk of unprovoked venous thromboembolic disease (VTE), likely related to the underlying inflammatory state and its pro-thrombotic nature [54-56]. Although the specific trigger for increased VTE risk is as of yet unclear, increased presence of antiphospholipid antibodies has been observed in this population, possibly contributing to the high rate of venous thrombosis [57]. The highest risk was found in patients within 12 months of SSc diagnosis and is 
strongly associated with female sex, atrial fibrillation, and heart failure. Trauma and glucocorticoid use were independently associated with DVT, although surgery alone was not, which may be related to the common use of prophylactic anticoagulation in the perioperative period. Anemia, likely related to marrow aplasia or malnutrition, is common in patients with SSc [58]. In conclusion, SSc is a disease process with numerous perioperative implications of which the most clinically relevant findings are summarized in Fig. 1.

\section{Intraoperative Considerations}

Few studies offer guidance on the specific perioperative care of SSc patients and many of these are based on observations from case reports or series. Incidental findings of difficult intravenous access in case reports of systemic sclerosis are common [59-61]. Due to skin thickening, intravenous access may pose a challenge, and it is reasonable to have a low threshold for ultrasound guidance for vascular catheter

\begin{tabular}{|c|c|c|}
\hline $\begin{array}{c}\text { Preoperative Risk Identification and } \\
\text { Stratification }\end{array}$ & $\begin{array}{l}\text { Intra-operative Risk } \\
\text { Mitigation }\end{array}$ & $\begin{array}{l}\text { Postoperative Complication } \\
\text { Surveillance }\end{array}$ \\
\hline $\begin{array}{l}\text { Airway. } \\
\text { Microstomia } \\
\text { Limited cervical extension }\end{array}$ & $\begin{array}{l}\text { Difficult airway } \\
\text { preparedness }\end{array}$ & $\begin{array}{l}\text { Sleep disordered breathing risk: } \\
\text { Continuous postoperative pulse } \\
\text { oximetry }\end{array}$ \\
\hline $\begin{array}{l}\text { Neurological } \\
\text { Peripheral neuropathies } \\
\text { (paresthesias, numbness) } \\
\text { Autonomic dysfunction risk factors } \\
\text { (orthostatic hypotension) }\end{array}$ & $\begin{array}{l}\text { Appropriate padding and } \\
\text { positioning }\end{array}$ & $\begin{array}{l}\text { Increased myocardial infarction } \\
\text { risk: } \\
\text { Continuous postoperative } \\
\text { telemetry }\end{array}$ \\
\hline $\begin{array}{l}\text { Pulmonary Hypertension risk factors } \\
\text { (dyspnea, increased PASP, RVSP) } \\
\text { Progressive cardiomyopathy - (TTE) } \\
\text { Conduction abnormalities - (EKG) }\end{array}$ & $\begin{array}{l}\text { Availability of ultrasound } \\
\text { for difficult Intravenous } \\
\text { access } \\
\text { Cardiac monitoring } \\
\text { Arterial line, possible TEE, } \\
\text { PA catheter }\end{array}$ & $\begin{array}{l}\text { ILD deterioration } \\
\text { Presence of increased oxygen } \\
\text { requirements }>24 \text { hours after } \\
\text { surgery. } \\
\text { Consider early workup for } \\
\text { postoperative pneumonia or } \\
\text { exacerbation of ILD }\end{array}$ \\
\hline $\begin{array}{l}\text { ILD risk factors } \\
\text { DLCO }<50 \% \\
C R P \geq 5 \text { or } E S R \geq 20 \\
\text { Decreased } 6 \text {-minute walk test }\end{array}$ & $\begin{array}{l}\text { Lung protective ventilation } \\
\text { strategy }\end{array}$ & $\begin{array}{l}\text { Venous thromboembolic disease } \\
\text { Surveillance in surgery, trauma } \\
\text { and those administered } \\
\text { perioperative glucocorticoids }\end{array}$ \\
\hline $\begin{array}{l}\text { Sleep disordered breathing risk } \\
\text { (apnea, daytime somnolence) } \\
\text { STOP-BANG questionnaire } \\
\text { Sleep study findings }\end{array}$ & Ensure adequate & $\begin{array}{l}\text { Scleroderma renal crisis risk } \\
\text { Refractory HTN, encephalopathy, } \\
\text { CHF }\end{array}$ \\
\hline
\end{tabular}

\begin{tabular}{|l|}
\hline Esophageal Dilation \\
\hline GERD symptoms \\
\hline Malnutrition \\
\hline $\begin{array}{l}\text { Pseudo-obstruction } \\
\text { Presence of sarcopenia }\end{array}$ \\
\hline
\end{tabular}

Venous thromboembolic disease risk factors

SSC diagnosis $<12$ months

Atrial fibrillation

Congestive heart failure

Anemia

Preoperative complete blood count

Abbreviations: RVSP=right ventricular systolic pressure; TTE=transthoracic echocardiography; EKG=electrocardiogram; ILD=interstitial lung disease; $D L C O=$ diffusing capacity of carbon monoxide; $C R P=c$-reactive protein; STOP-BANG=Snoring Tiredness, Observed apnea, blood Pressure, Body mass index, Age, Neck circumference, and gender, HTN=hypertension; $\mathrm{CHF}=$ congestive heart failure; $\mathrm{SSc}=$ systemic sclerosis $\mathrm{PASP}=$ pulmonary artery systolic pressure

Fig. 1 Perioperative optimization in systemic sclerosis. The salient points in the perioperative optimization of patients with SSc are highlighted 
insertion [62]. Airway management may pose a problem in SSc. There are reports of microstomia and restricted mouth opening, likely related to temporomandibular joint fibrosis, and fibrotic changes of the neck resulting in poor cervical extension [63, 64]. In addition, reports have emphasized the presence of limited cervical extension as an indicator of both difficult mask ventilation and need for fiberoptic bronchoscopy assisted intubation [63]. The recent data on airway management is summarized in Table 3. In addition, since approximately $90 \%$ of SSc patients have GERD and other gastrointestinal dysmotility disorders, a higher than normal aspiration risk is likely [65]. Indeed, a high prevalence of esophageal dilation is common and may be associated with an increased risk of centrilobular fibrosis of the lung, emphasizing the complex interplay between the pathophysiologic findings in SSc [66]. Appropriate preoperative precautions such as the administration of a histamine-2 $\left(\mathrm{H}_{2}\right)$ blocker and when appropriate, preoperative nasogastric suctioning, should be strongly considered. This recommendation is particularly strong since aspiration events are independently associated with risk of death in hospitalized SSc patients [67]. Nasogastric tube placement is performed with caution due to the high incidence of esophageal stricture disease in patients with SSc, increasing the already high-risk of esophageal perforation [68]. In addition, esophageal pathology may complicate placement of a transesophageal echocardiography (TEE) probe. Acknowledging the risk of difficult mask ventilation and endotracheal intubation, a rapid sequence intubation may not be advisable, and careful risk mitigation of aspiration should be considered before induction of general anesthesia. The potential perioperative risk for peripheral neuropathies should be mitigated with appropriate positioning and padding.

Given the common occurrence of cardiac involvement in SSc, intraoperative care should focus on close hemodynamic monitoring commensurate with the complexity of the surgical procedure. Dysrhythmias, likely drug enhanced, have been reported in patients with SSc and may lead to increased perioperative risk. In patients with pre-existing PAH or PH (pulmonary hypertension), poor right ventricular performance will likely be exacerbated by high intraoperative fluid loads, metabolic acidosis, and surgical stress resulting in deteriorating hemodynamics. Although little evidence is available to support their use, invasive monitoring may be advisable, dependent on the procedure and severity of disease. Thus, the benefits and risks should be carefully weighed before placement of pulmonary artery catheters and TEE probes in SSc patients. The severity of the PAH or PH may require inotropic agents (sympathomimetic and non-sympathomimetic vasopressors), vasodilators such as nitric oxide, and inhaled prostacyclin analogues.

Substantial ventilator-related harm may be induced in SSc patients with ILD, and efforts should be made to minimize the use of invasive mechanical ventilation. This observation is

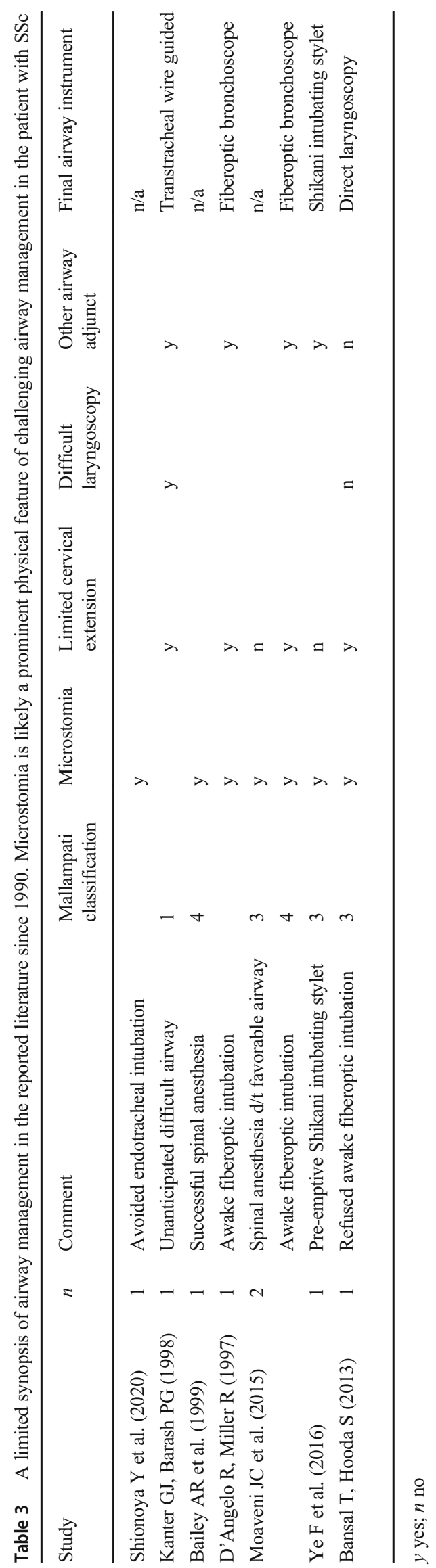


supported by a meta-analysis of 15 studies that examined risk factors for intensive care unit-related mortality in a mixed ILD population and found a strong correlation between mortality and the application of invasive mechanical ventilation [69]. A study of SSc-related intensive care admission outcomes found higher mortality in patients with diffuse cutaneous $\mathrm{SSc}(72.5 \%)$, pulmonary fibrosis $(71.7 \%)$, and/or pulmonary hypertension (31.5\%) [70]. In-hospital mortality and 6month mortality were $31.8 \%$ and $39.0 \%$, respectively, and the majority were admitted with respiratory failure. This study also found a strong correlation between invasive mechanical ventilation and mortality. Another study found that a DLCO < $50 \%$ is a strong predictor for cardiopulmonary-related hospitalization in patients with SSc and pulmonary hypertension [71•]. Furthermore, acute exacerbations of ILD may also be more common in SSc compared with other ILD-related conditions and show increased mortality with invasive ventilation [72]. Although specific guidance concerning mechanical ventilation in SSc-related ILD is lacking, prudence dictates the use of perioperative lung protective ventilation strategies [73].

Given the evidence that invasive ventilation may contribute to SSc-related morbidity, it is reasonable to extrapolate that the appropriate use of regional or neuraxial techniques should be considered in the care of this patient population when possible. Regional and neuraxial techniques have been successfully performed in patients with SSc but may be technically challenging [74-76]. Furthermore, autonomic nervous system dysfunction may exacerbate hemodynamic effects of neuraxial anesthesia. Uneventful spinal anesthesia for cesarean section has been reported, but severe hypotension requiring treatment has been noted $[60,77,78]$. Prolonged sensory blockade has been reported and may be related to tissue $\mathrm{pH}$ difference reducing the unionized fraction of local anesthetic, or peripheral vascular insufficiency at the regional block location causing reduced clearance $[75,79,80]$. Furthermore, the increasing application of ultrasound guidance has likely reduced the need for high-volume local anesthetic for regional anesthesia, further reducing the risk of prolonged block. It is highly probable that obstetric anesthesia is safe, but parturients with SSc should be considered high-risk, necessitating a high level of preparedness and multi-disciplinary team involvement. Furthermore, the limited data suggests that, though it may be technically difficult, neuraxial and regional anesthesia are safe and should be encouraged in patients with SSc for all eligible procedures particularly with ultrasound guidance.

\section{Postoperative Considerations}

Postoperative vigilance remains the mainstay of safe perioperative care. Several aspects of postoperative monitoring should be considered after surgical intervention. SSc patients may be at risk for postoperative sleep-disordered breathing has been reported with $31.2 \%$ of patients having abnormal pulse oximetry readings on sleep studies [81]. This suggests that SSc patients may benefit from close postoperative ventilatory monitoring. Secondly, the increased SSc-specific risk for myocardial infarction should trigger close postoperative scrutiny. General principles for the care of SSc patients with $\mathrm{PH}$ or PAH continue through the postoperative time period. Meticulous attention to maintaining sinus rhythm, avoiding right ventricular stress, avoiding excessive hypercarbia, and early correction of metabolic abnormalities are important. Given the high incidence of ILD, symptoms of acute postoperative respiratory worsening, postoperative pneumonia, or acute exacerbation of ILD are addressed expeditiously. These adverse events are potentially high-mortality events in patients with SSc. The relationship of SRC and perioperative care is unclear, but close monitoring, particularly for signs and symptoms of refractory hypertension and aggressive management of deteriorating kidney function, should be considered. Furthermore, aggressive venous thromboembolic prophylaxis should be considered in most SSc patients, particularly those with a recent $(<12$ months) diagnosis, atrial fibrillation, or cardiomyopathy.

\section{Conclusion}

Recent advances in the understanding and management of SSc have resulted in substantial improvements in survival. As many SSc patients continue to age with comorbidities such as PAH and ILD, it is likely that many will present for surgical interventions. Given its systemic involvement, the anesthesiologist needs to carefully weigh the implications of anesthetic techniques, and their potential for interactions with the underlying pathophysiology of SSc. Secondly, patients with systemic sclerosis often have well-compensated mechanisms for their underlying disease, which may be unmasked with anesthetic interventions. A difficult airway and a potential risk for aspiration should be anticipated, and appropriate preoperative preparation should be emphasized. Furthermore, SSc patients are at risk for postoperative myocardial infarction, and prolonged mechanical ventilation may result in substantial morbidity, specifically in those patients with ILD. Many questions remain, and further research is needed to better identify perioperative risk factors and determine optimal perioperative strategies in the care of these complex patients.

\section{Availability of Data and Materials N/a}

Authors' Contributions All authors engaged in the study conception and design. Material preparation, data aggregation, and initial draft of the manuscript were performed by ZJC. All authors commented, amended, and modified previous versions of the manuscript. All authors approved the final manuscript. 


\section{Compliance with Ethical Standards}

Conflicts of Interest None of the authors has any potential conflicts of interest to disclose.

\section{Ethics Approval N/a}

Human and Animal Rights and Informed Consent This article does not contain any studies performed by the co-authors that had human or animal subjects.

\section{References}

Papers of particular interest, published recently, have been highlighted as:

- Of importance

•- Of major importance

1. Katsumoto TR, Whitfield ML, Connolly MK. The pathogenesis of systemic sclerosis. Annu Rev Pathol. 2011;6:509-37. https://doi. org/10.1146/annurev-pathol-011110-130312.

2. LeRoy EC, Medsger TA Jr. Criteria for the classification of early systemic sclerosis. J Rheumatol. 2001;28(7):1573-6.

3. Hachulla E, Launay D. Diagnosis and classification of systemic sclerosis. Clin Rev Allergy Immunol. 2011;40(2):78-83. https:// doi.org/10.1007/s12016-010-8198-y.

4. van den Hoogen F, Khanna D, Fransen J, Johnson SR, Baron M, Tyndall A, et al. 2013 classification criteria for systemic sclerosis: an American College of Rheumatology/European League against Rheumatism collaborative initiative. Arthritis Rheum. 2013;65(11): 2737-47. https://doi.org/10.1002/art.38098.

5. Barnes J, Mayes MD. Epidemiology of systemic sclerosis: incidence, prevalence, survival, risk factors, malignancy, and environmental triggers. Curr Opin Rheumatol. 2012;24(2):165-70. https:// doi.org/10.1097/BOR.0b013e32834ff2e8.

6. Steen VD, Medsger TA. Changes in causes of death in systemic sclerosis, 1972-2002. Ann Rheum Dis. 2007;66(7):940-4. https:// doi.org/10.1136/ard.2006.066068.

7. Tyndall AJ, Bannert B, Vonk M, Airo P, Cozzi F, Carreira PE, et al. Causes and risk factors for death in systemic sclerosis: a study from the EULAR Scleroderma Trials and Research (EUSTAR) database. Ann Rheum Dis. 2010;69(10):1809-15. https://doi.org/10.1136/ $\operatorname{ard} .2009 .114264$.

8. Smith GB, Shribman AJ. Anaesthesia and severe skin disease. Anaesthesia. 1984;39(5):443-55. https://doi.org/10.1111/j.13652044.1984.tb07313.x.

9. Herrick AL. Neurological involvement in systemic sclerosis. Br J Rheumatol. 1995;34(11):1007-8. https://doi.org/10.1093/ rheumatology/34.11.1007.

10. Amaral TN, Peres FA, Lapa AT, Marques-Neto JF, Appenzeller S. Neurologic involvement in scleroderma: a systematic review. Semin Arthritis Rheum. 2013;43(3):335-47. https://doi.org/10. 1016/j.semarthrit.2013.05.002.

11. Gilston A. Raynaud's phenomenon and propofol. Anaesthesia. 1999;54(3):307. https://doi.org/10.1046/j.1365-2044.1999.0811v. $\mathrm{x}$.

12. Dodd PH, Biswas G. Raynaud's phenomenon and propofol. Anaesthesia. 1999;54(9):918. https://doi.org/10.1046/j.1365-2044. 1999.01096.x.
13. Dessein PH, Gledhill RF. More on autonomic neuropathy in systemic sclerosis. Ann Rheum Dis. 1988;47(3):261-3. https://doi.org/ 10.1136/ard.47.3.261-b.

14. Gledhill RF, Dessein PH. Systemic sclerosis: another disease with autonomic dysfunction. Ann Neurol. 1988;23(4):421-2. https://doi. org/10.1002/ana.410230428.

15. Klimiuk PS, Taylor L, Baker RD, Jayson MI. Autonomic neuropathy in systemic sclerosis. Ann Rheum Dis. 1988;47(7):542-5. https://doi.org/10.1136/ard.47.7.542.

16. Psarras A, Soulaidopoulos S, Garyfallos A, Kitas G, Dimitroulas T. A critical view on cardiovascular risk in systemic sclerosis. Rheumatol Int. 2017;37(1):85-95. https://doi.org/10.1007/s00296016-3530-3.

17.• Bissell LA, Anderson M, Burgess M, Chakravarty K, Coghlan G, Dumitru RB, et al. Consensus best practice pathway of the UK Systemic Sclerosis Study group: management of cardiac disease in systemic sclerosi. Rheumatology (Oxford). 2017;56(6):912-21. https://doi.org/10.1093/rheumatology/kew488 A comprehensive review of the management of SSc-related cardiac disease.

18. Aviña-Zubieta JA, Man A, Yurkovich M, Huang K, Sayre EC, Choi HK. Early cardiovascular disease after the diagnosis of systemic sclerosis. Am J Med. 2016;129(3):324-31. https://doi.org/10. 1016/j.amjmed.2015.10.037.

19. Nikai T, Kanata K, Ozasa H, Uchida H. Suddenly developing low output syndrome during acute thoracic aortic dissection surgery in a patient with progressive systemic sclerosis. Masui. 2002;51(2): $182-5$.

20. Tung A, Sweitzer B, Cutter T. Cardiac arrest after labetalol and metoclopramide administration in a patient with scleroderma. Anesthesia and Analgesia. 2002;95(6):1667-1668, table of contents. https://doi.org/10.1097/00000539-200212000-00035.

21. Kihira C, Mizutani H, Shimizu M. Sinus arrest developed during gastric cancer operation in a progressive systemic sclerosis patient. J Dermatol. 1995;22(5):357-9. https://doi.org/10.1111/j.13468138.1995.tb03404.x.

22.• Luo Y, Jiang C, Krittanawong C, Arevalo Molina AB, Murray S, Huang F, et al. Systemic sclerosis and the risk of perioperative major adverse cardiovascular events for inpatient non-cardiac surgery. Int J Rheum Dis. 2019;22(6):1023-8. https://doi.org/10.1111/ 1756-185x.13537 A comprehensive analysis of SSc-related perioperative cardiac events.

23. Mukerjee D, St George D, Coleiro B, Knight C, Denton CP, Davar $\mathrm{J}$, et al. Prevalence and outcome in systemic sclerosis associated pulmonary arterial hypertension: application of a registry approach. Ann Rheum Dis. 2003;62(11):1088-93. https://doi.org/10.1136/ ard.62.11.1088.

24. Launay D, Sobanski V, Hachulla E, Humbert M. Pulmonary hypertension in systemic sclerosis: different phenotypes. Eur Respir Rev. 2017;26(145). https://doi.org/10.1183/16000617.0056-2017.

25. Pilkington SA, Taboada D, Martinez G. Pulmonary hypertension and its management in patients undergoing non-cardiac surgery. Anaesthesia. 2015;70(1):56-70. https://doi.org/10.1111/anae. 12831 A focused review of perioperative pulmonary hypertension and its management.

26. Giacomelli R, Liakouli V, Berardicurti O, Ruscitti P, Di Benedetto $\mathrm{P}$, Carubbi $\mathrm{F}$, et al. Interstitial lung disease in systemic sclerosis: current and future treatment. Rheumatol Int. 2017;37(6):853-63. https://doi.org/10.1007/s00296-016-3636-7.

27. Wijeysundera DN, Beattie WS. Calcium channel blockers for reducing cardiac morbidity after noncardiac surgery: a meta-analysis. Anesth Analg. 2003;97(3):634 41. https://doi.org/10.1213/01.ane. 0000081732.51871.d2.

28. Kuypers DR. Immunotherapy in elderly transplant recipients: a guide to clinically significant drug interactions. Drugs Aging. 2009;26(9):715-37. https://doi.org/10.2165/11316480000000000-00000. 
29. Gramstad L. Atracurium, vecuronium and pancuronium in endstage renal failure. Dose-response properties and interactions with azathioprine. Br J Anaesth. 1987;59(8):995-1003. https://doi.org/ 10.1093/bja/59.8.995.

30. Groves DS, Blum FE, Huffmyer JL, Kennedy JL, Ahmad HB, Durieux ME, et al. Effects of early inhaled epoprostenol therapy on pulmonary artery pressure and blood loss during LVAD placement. J Cardiothorac Vasc Anesth. 2014;28(3):652-60. https://doi. org/10.1053/j.jvca.2013.05.028.

31. Xia Z, Kuo KH, McNeill JH, Ansley DM. Endothelin A and B receptor antagonist bosentan reduces postischemic myocardial injury in the rat: critical timing of administration. Can J Physiol Pharmacol. 2005;83(3):259-66. https://doi.org/10.1139/y05-014.

32. Konrad D, Oldner A, Wanecek M, Rudehill A, Weitzberg E, Biber $\mathrm{B}$, et al. Positive inotropic and negative lusitropic effects of endothelin receptor agonism in vivo. Am J Physiol Heart Circ Physiol. 2005;289(4):H1702-9. https://doi.org/10.1152/ajpheart. 00892.2004.

33. Fodale V, Di Pietro R, Santamaria S. Viagra, surgery and anesthesia: a dangerous cocktail with a risk of blindness. Med Hypotheses. 2007;68(4):880-2. https://doi.org/10.1016/j.mehy.2006.08.031.

34. Vassalos A, Peng E, Young D, Walker S, Pollock J, Macarthur K, et al. Pre-operative sildenafil and pulmonary endothelial-related complications following cardiopulmonary bypass: a randomised trial in children undergoing cardiac surgery. Anaesthesia. 2011;66(6):47280. https://doi.org/10.1111/j.1365-2044.2011.06702.x.

35. Elkoundi A, Tahri A, Meziane M, Bensghir M, Lalaoui SJ. Sildenafil related cerebral venous thrombosis following spinal anesthesia. J Clin Anesth. 2017;42:47-8. https://doi.org/10.1016/j. jclinane.2017.08.011.

36. Bălănescu AR, Bojincă VC, Bojincă M, Donisan T, Bălănescu SM. Cardiovascular effects of methotrexate in immune-mediated inflammatory diseases. Experimental and Therapeutic Medicine. 2019;17(2):1024-9. https://doi.org/10.3892/etm.2018.6992.

37. Kim DH, Rogers JR, Fulchino LA, Kim CA, Solomon DH, Kim SC. Bisphosphonates and risk of cardiovascular events: a metaanalysis. PLoS One. 2015;10(4):e0122646. https://doi.org/10. 1371/journal.pone. 0122646 .

38. Chung L, Chen H, Khanna D, Steen VD. Dyspnea assessment and pulmonary hypertension in patients with systemic sclerosis: utility of the University of California, San Diego, Shortness of Breath Questionnaire. Arthritis Care Res (Hoboken). 2013;65(3):454-63. https://doi.org/10.1002/acr.21827.

39. Rizzi M, Radovanovic D, Santus P, Airoldi A, Frassanito F, Vanni $\mathrm{S}$, et al. Usefulness of six-minute walk test in systemic sclerosis. Clin Exp Rheumatol. 2018;36 Suppl 113(4):161-167.

40. Vandecasteele E, De Pauw M, De Keyser F, Decuman S, Deschepper E, Piette Y, et al. Six-minute walk test in systemic sclerosis: a systematic review and meta-analysis. Int J Cardiol. 2016;212:265-73. https://doi.org/10.1016/j.ijcard.2016.03.084.

41. Vandecasteele E, Melsens K, De Keyser F, De Pauw M, Deschepper E, Decuman S, et al. A prospective, longitudinal study evaluating the baseline six-minute walk test as an individual reference value in systemic sclerosis patients. Clin Exp Rheumatol. 2018;36 Suppl 113(4):95-101.

42. Bonifazi M, Sverzellati N, Negri E, Pomponio G, Seletti V, Bonini $\mathrm{M}$, et al. Increased prevalence of small airways dysfunction in patients with systemic sclerosis as determined by impulse oscillometry. Rheumatology (Oxford). 2019. https://doi.org/10. 1093/rheumatology/kez340.

43. Ross L, Stevens W, Rabusa C, Wilson M, Ferdowsi N, Walker J, et al. The role of inflammatory markers in assessment of disease activity in systemic sclerosis. Clin Exp Rheumatol. 2018;36 Suppl 113(4):126-134.

44. Marie I, Levesque H, Ducrotté P, Denis P, Hellot MF, Benichou J, et al. Gastric involvement in systemic sclerosis: a prospective study.
Am J Gastroenterol. 2001;96(1):77-83. https://doi.org/10.1111/j. 1572-0241.2001.03353.x.

45. Brandler JB, Sweetser S, Khoshbin K, Babameto M, Prokop LJ, Camilleri M. Colonic manifestations and complications are relatively under-reported in systemic sclerosis: a systematic review. Am J Gastroenterol. 2019;114(12):1847-56. https://doi.org/10.14309/ ajg.0000000000000397.

46. Richard N, Hudson M, Wang M, Gyger G, Proudman S, Stevens $\mathrm{W}$, et al. Severe gastrointestinal disease in very early systemic sclerosis is associated with early mortality. Rheumatology (Oxford). 2019;58(4):636-44. https://doi.org/10.1093/rheumatology/key350.

47. Dupont R, Longué M, Galinier A, Cinq Frais C, Ingueneau C, Astudillo L, et al. Impact of micronutrient deficiency \& malnutrition in systemic sclerosis: cohort study and literature review. Autoimmun Rev. 2018;17(11):1081-9. https://doi.org/10.1016/j. autrev.2018.05.010.

48. Caimmi C, Caramaschi P, Venturini A, Bertoldo E, Vantaggiato E, Viapiana $\mathrm{O}$, et al. Malnutrition and sarcopenia in a large cohort of patients with systemic sclerosis. Clin Rheumatol. 2018;37(4):98797. https://doi.org/10.1007/s10067-017-3932-y.

49. Rigamonti C, Shand LM, Feudjo M, Bunn CC, Black CM, Denton $\mathrm{CP}$, et al. Clinical features and prognosis of primary biliary cirrhosis associated with systemic sclerosis. Gut. 2006;55(3):388-94. https:// doi.org/10.1136/gut.2005.075002.

50. Assassi S, Fritzler MJ, Arnett FC, Norman GL, Shah KR, Gourh P, et al. Primary biliary cirrhosis (PBC), PBC autoantibodies, and hepatic parameter abnormalities in a large population of systemic sclerosis patients. J Rheumatol. 2009;36(10):2250-6. https://doi. org/10.3899/jrheum.090340.

51. Ziser A, Plevak DJ, Wiesner RH, Rakela J, Offord KP, Brown DL. Morbidity and mortality in cirrhotic patients undergoing anesthesia and surgery. Anesthesiology. 1999;90(1):42-53. https://doi.org/10. 1097/00000542-199901000-00008.

52. Desbois AC, Cacoub P. Systemic sclerosis: an update in 2016. Autoimmun Rev. 2016;15(5):417-26. https://doi.org/10.1016/j. autrev.2016.01.007.

53. Mouthon L, Bérezné A, Bussone G, Noël LH, Villiger PM, Guillevin L. Scleroderma renal crisis: a rare but severe complication of systemic sclerosis. Clin Rev Allergy Immunol. 2011;40(2): 84-91. https://doi.org/10.1007/s12016-009-8191-5.

54. Schoenfeld SR, Choi HK, Sayre EC, Aviña-Zubieta JA. Risk of pulmonary embolism and deep venous thrombosis in systemic sclerosis: a general population-based study. Arthritis Care Res (Hoboken). 2016;68(2):246-53. https://doi.org/10.1002/acr.22673.

55. Zöller B, Li X, Sundquist J, Sundquist K. Risk of pulmonary embolism in patients with autoimmune disorders: a nationwide followup study from Sweden. Lancet (London, England). 2012;379(9812):244-9. https://doi.org/10.1016/s0140-6736(11) 61306-8.

56. Chung WS, Lin CL, Sung FC, Hsu WH, Yang WT, Lu CC, et al. Systemic sclerosis increases the risks of deep vein thrombosis and pulmonary thromboembolism: a nationwide cohort study. Rheumatology (Oxford). 2014;53(9):1639-45. https://doi.org/10. 1093/rheumatology/keu133.

57. Touré AO, Ly F, Sall A, Diatta A, Gadji M, Seck M, et al. Antiphospholipid antibodies and systemic scleroderma. Turk J Haematol. 2013;30(1):32-6. https://doi.org/10.4274/tjh.2012. 0059.

58. Westerman MP, Martinez RC, Medsger TA Jr, Totten RS, Rodnan GP. Anemia and scleroderma: frequency, causes, and marrow findings. Arch Intern Med. 1968;122(1):39-42.

59. Ye F, Kong G, Huang J. Anesthetic management of a patient with localised scleroderma. Springerplus. 2016;5(1):1507. https://doi. org/10.1186/s40064-016-3189-y.

60. Moaveni D, Cohn J, Brodt J, Hoctor K, Ranasinghe J. Scleroderma and pulmonary hypertension complicating two pregnancies: use of 
neuraxial anesthesia, general anesthesia, epoprostenol and a multidisciplinary approach for cesarean delivery. Int J Obstet Anesth. 2015;24(4):375-82. https://doi.org/10.1016/j.ijoa.2015.05.001.

61. Bansal T. Emergency surgery in a patient with scleroderma Anaesthetic challenges: a case report. The Indian Anaesthetists' Forum. 2013;14:1-4.

62. D'Angelo R, Miller R. Pregnancy complicated by severe preeclampsia and thrombocytopenia in a patient with scleroderma. Anesth Analg. 1997;85(4):839-41. https://doi.org/10.1097/ 00000539-199710000-00023.

63. Kanter GJ, Barash PG. Undiagnosed scleroderma in a patient with a difficult airway. Yale J Biol Med. 1998;71(1):31-3.

64. Shionoya Y, Kamiga H, Tsujimoto G, Nakamura E, Nakamura K, Sunada K. Anesthetic management of a patient with systemic sclerosis and microstomia. Anesth Prog. 2020;67(1):28-34. https://doi. org/10.2344/anpr-66-03-07.

65. Sallam H, McNearney TA, Chen JD. Systematic review: pathophysiology and management of gastrointestinal dysmotility in systemic sclerosis (scleroderma). Aliment Pharmacol Ther. 2006;23(6):691-712. https://doi.org/10.1111/j.1365-2036.2006. 02804.x.

66. Christmann RB, Wells AU, Capelozzi VL, Silver RM. Gastroesophageal reflux incites interstitial lung disease in systemic sclerosis: clinical, radiologic, histopathologic, and treatment evidence. Semin Arthritis Rheum. 2010;40(3):241-9. https://doi.org/ 10.1016/j.semarthrit.2010.03.002.

67. Sehra ST, Kelly A, Baker JF, Derk CT. Predictors of inpatient mortality in patients with systemic sclerosis: a case control study. Clin Rheumatol. 2016;35(6):1631-5. https://doi.org/10.1007/ s10067-016-3245-6.

68. Ebert EC, Ruggiero FM, Seibold JR. Intestinal perforation. A common complication of scleroderma. Dig Dis Sci. 1997;42(3):549-53. https://doi.org/10.1023/a:1018847126143.

69. Huapaya JA, Wilfong EM, Harden CT, Brower RG, Danoff SK. Risk factors for mortality and mortality rates in interstitial lung disease patients in the intensive care unit. Eur Respir Rev. 2018;27(150). https://doi.org/10.1183/16000617.0061-2018.

70. Pène F, Hissem T, Bérezné A, Allanore Y, Geri G, Charpentier J, et al. Outcome of patients with systemic sclerosis in the intensive care unit. J Rheumatol. 2015;42(8):1406-12. https://doi.org/10.3899/ jrheum.141617.

71. Hsu VM, Chung L, Hummers LK, Shah A, Simms R, Bolster M, et al. Risk factors for mortality and cardiopulmonary hospitalization in systemic Sclerosis patients at risk for pulmonary hypertension, in the PHAROS registry. J Rheumatol. 2019;46(2):176-83. https:// doi.org/10.3899/jrheum.180018 A detailed analysis of factors associated with cardiopulmonary morbidity in patients with SSc.

72. Singh P, Thakur B, Mohapatra AK, Padhan P. Clinical features and outcome of acute exacerbation in connective tissue disease-associated interstitial lung disease: a single-center study from India. Int $\mathbf{J}$ Rheum Dis. 2019;22(9):1741-5. https://doi.org/10.1111/1756$185 x .13666$

73. Young CC, Harris EM, Vacchiano C, Bodnar S, Bukowy B, Elliott $\mathrm{RRD}$, et al. Lung-protective ventilation for the surgical patient: international expert panel-based consensus recommendations. Br J Anaesth. 2019;123(6):898-913. https://doi.org/10.1016/j.bja.2019. 08.017.

74. Ceylan BG, Sari Ak S, Ozorak O, Yavuz L, Eroglu F. Combined femoral and sciatic nerve block in a cachectic progressive systemic sclerosis case with gastrointestinal and cardiac involvement. Agri. 2010;22(4):165-9.

75. Dempsey ZS, Rowell S, McRobert R. The role of regional and neuroaxial anesthesia in patients with systemic sclerosis. Local Reg Anesth. 2011;4:47-56. https://doi.org/10.2147//ra.s23808.

76. Erk G, Taspinar V, Donmez F, Ornek D. Neuroaxial anesthesia in a patient with progressive systemic sclerosis : case presentation and review of the literature on systemic sclerosis. BMC Anesthesiol. 2006;6:11. https://doi.org/10.1186/1471-2253-6-11.

77. Lee GY, Cho S. Spinal anesthesia for cesarean section in a patient with systemic sclerosis associated interstitial lung disease: a case report. Korean J Anesthesiol. 2016;69(4):406-8. https://doi.org/10. 4097/kjae.2016.69.4.406.

78. Bailey AR, Wolmarans M, Rhodes S. Spinal anaesthesia for caesarean section in a patient with systemic sclerosis. Anaesthesia. 1999;54(4):355-8. https://doi.org/10.1046/j.1365-2044.1999. 00751.x.

79. Thompson J, Conklin KA. Anesthetic management of a pregnant patient with scleroderma. Anesthesiology. 1983;59(1):69-71. https://doi.org/10.1097/00000542-198307000-00012.

80. Lewis GB. Prolonged regional analgesia in scleroderma. Can Anaesth Soc J. 1974;21(5):495-7. https://doi.org/10.1007/ bf03005844.

81. Nokes BT, Raza HA, Cartin-Ceba R, Lyng PJ, Krahn LE, Wesselius L, et al. Individuals with scleroderma may have increased risk of sleep-disordered breathing. Journal of Clinical Sleep Medicine. 2019;15(11):1665-9. https://doi.org/10.5664/ jesm. 8036 .

Publisher's Note Springer Nature remains neutral with regard to jurisdictional claims in published maps and institutional affiliations. 